\title{
Sistem Pendukung Keputusan Penentuan Lahan Kritis Menggunakan Preference Ranking Organization Method For Enrichment Evaluation (Promethee)
}

\author{
Yudi Eko Windarto ${ }^{1}$, Harits Fathuddin ${ }^{2}$, Oky Dwi Nurhayati ${ }^{3}$ \\ 1,2,3 Departemen Teknik Komputer, Fakultas Teknik, Universitas Diponegoro, ${ }^{1}$ yudi@live.undip.ac.id, \\ hfathuddin@student.ce.undip.ac.id, 3okidwi.n@gmail.com
}

\begin{abstract}
Critical land becomes a specific problem in data processing in the environmental field. Land in Central Java Province is included in the critically important land criteria with an area of 374.000 hectares. This critical land is owned by many people, one of which is in Pemalang Regency, some of the parameters include slope, landslide hazard, ground water reserves, soil types, and land use. Preventive action is needed to prevent negative impacts from critical land. Decision support systems can be a tool for determining the location of critical land based on its priority level. Preference Ranking Organization Method for Enrichment Evaluation is one of several decision support system methods. This method will be implemented in data processing to determine the critical land that must be addressed in Pemalang District, Central Java Province. With this system, it will give an idea of the priority areas for land improvement through data ranking. This system was built using PHP programming language and MySQL database. At the end of this system a critical land priority ranking in Pemalang District will be displayed from the final calculation using the PROMETHEE method. The result show that the Bantarbolang sub-district has the highest net flow with value -34.10 as the region with the highest critical land priority.
\end{abstract}

Keywords: Promethee, Decision Support Systems, Critical Land, PHP, MySQL

\section{Pendahuluan}

Lahan kritis terjadi akibat perubahan penggunaan lahan di Indonesia dari kawasan lahan pertanian maupun lahan hutan menjadi lahan non pertanian atau lahan terbangun sehingga kawasan yang berfungsi sebagai serapan air semakin berkurang yang dapat menyebabkan degradasi lahan, kekeringan atau kekurangan air bersih pada musim kemarau, bencana tanah longsor dan bencana banjir pada musim penghujan[1]. Balai Pengelolaan Daerah Aliran Sungai (BPDAS) Kabupaten Pemalang memiliki daerah kritis untuk hutan lindung dan hutan konservasi terluas di Jawa Tengah yakni sebesar $7.01 \%$ atau setara dengan 2871.5 ha. Parameter yang menjadi faktor kekritisan lahan, yaitu tingkat bahaya erosi, produktifitas lahan, erosi lahan, manajemen lahan, singkapan batuan, kemiringan lereng, dan curah hujan[2].

Kabupaten Kendal memiliki kondisi topografi yang cukup beragam dimana terdapat perbukitan, dataran dan pesisir. Menurut Dinas Pertanian, Perkebunan dan Kehutanan Kabupaten Kendal bahwa pada tahun 2009 sampai dengan
2013, pada wilayah bagian selatan memiliki sebaran lahan kritis lebih banyak jika dibandingkan dengan kawasan dataran dan pesisir. Wilayah bagian selatan Kabupaten Kendal merupakan perbukitan dengan dominasi kemiringan lereng adalah $8-15 \%, 15-25 \%$ dan $>40 \%$. Meningkatnya jumlah penduduk baik kelahiran maupun migrasi di wilayah Kendal bagian utara menyebabkan kebutuhan akan tanah juga meningkat. Sedangkan jumlah tanah tidak dapat ditambah sehingga menggeser fungsi lahan tersebut. Peningkatan jumlah penduduk tiap tahunnya mendorong terjadinya perubahan penggunaan lahan sehingga memicu peningkatan luasan lahan kritis dari tahun ke tahun[3].

Dalam penelitian yang bertujuan untuk mengetahui perbedaan dengan penggunaan metode AHP (Analythical Hierarchy Process) [4] dalam pengambilan keputusan penerimaan beasiswa, disimpulkan bahwa perbedaan metode AHP dan PROMETHEE adalah metode AHP langsung memproses bobot pembanding disetiap alternatif dan kriteria, sedangkan metode 
Pengembangan Rekayasa dan Teknologi, Vol 15, No. 2, Desember 2019, pp 64-70

p-ISSN: $1410-9840$ \& e-ISSN: 2580-8850

http://journals.us m.ac.id/index.php/jprt/index

PROMETHEE mengharuskan pembuat keputusan untuk menentukan tipe preferensi terlebih dahulu.

Metode PROMETHEE adalah suatu metode penentuan urutan (prioritas) dalam Multi Criteria Decision Making (MCDM). Keunggulannya adalah kesederhanaan, kejelasan, dan kestabilan. Asumsi dari dominasi kriteria yang digunakan dalam PROMETHEE adalah penggunaan nilai dalam hubungan outranking[5]. Metode PROMETHEE juga digunakan untuk mengevaluasi sistem tanggap darurat dengan mempertimbangkan sinergi interaksi [6].

Dalam penelitian sebelumnya [7] yang bertujuan untuk pemilihan peserta pelatihan di BLK Bantul, disimpulkan setiap kriteria pada metode PROMETHEE ditentukan fungsi preferensinya sehingga dapat memberikan keputusan peringkat parsial dan lengkap. Metode PROMETHEE dapat diimplementasikan untuk merekomendasikan unit terbaik di PDAM Tirta Lihou, Kabupaten Simalungun karena memiliki penyelesaian kasus yang bersifat multi kompleks yang terdiri dari banyak alternatif, dan banyak kriteria[8].

Pemodelan dengan pendekatan Interval Valued Intuitionistic Fuzzy - PROMETHEE diterapkan untuk evaluasi kualitas layanan berdasarkan pandangan pasien dalam studi kasus pada rumah sakit umum di Istanbul. Metodologi yang digunakan sebagai rekomendasi sistem manajemen rumah sakit. [9].

Nugraha menyatakan [10] bahwa PROMETHEE (Preference Ranking Organization Method for Enrichment Evaluation) lebih efektif dalam membuat keputusan karena selalu dapat memberikan rekomendasi baik saat memiliki sedikit alternatif maupun banyak alternatif dibandingkan metode ELECTRE (Elimination And Choice Translating Reality).

Sehubungan dengan masalah lahan kritis, peneliti membangun aplikasi Preference Ranking Organization Method for Enrichment Evaluation sebagai Sistem Pendukung Keputusan Penentuan Lahan Kritis pada Kabupaten Pemalang, Provinsi Jawa Tengah.

\section{Metodologi}

Penelitian ini mengimplementasikan bagaimana penggunaan metode PROMETHEE sebagai sistem pendukung keputusan dalam hal ini sebagai penentu lahan kritis di Kabupaten Pemalang. Gambar 1. menunjukkan diagram alir dari metode penelitian yang dilakukan.

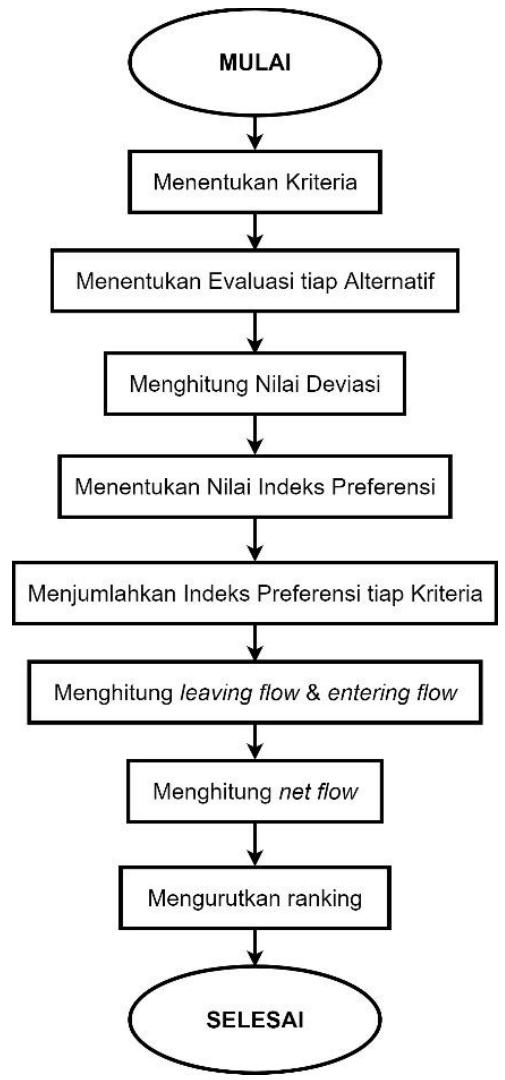

Gambar 1. Metode Penelitian

Analisis penentuan alternatif kriteria dengan metode PROMETHEE ini memiliki tahap - tahap sebagai berikut:

2.1 Pengumpulan data kriteria beserta data alternatifnya.

Data kriteria terdiri dari : kelerengan, penggunaan lahan, rawan bencana longsor, curah hujan, cadangan air tanah, dan jenis tanah $20 \%$. Sedangkan alternatifnya terdiri dari 14 kecamatan yaitu : Bodeh, Ulujami, Comal, Ampelgading, Petarukan, Taman, Pemalang, Bantarbolang, Randudongkal, Warungpring, Moga, Pulosari, Watukumpul, Belik.

2.2 Menentukan bobot pada masing - masing kriteria. 
Pengembangan Rekayasa dan Teknologi, Vol 15, No. 2, Desember 2019, pp 64-70

Kriteria yang digunakan adalah kelerengan dengan presentase $15 \%$, penggunaan lahan $20 \%$, rawan bencana longsor $10 \%$, curah hujan $15 \%$, cadangan air tanah $20 \%$, dan jenis tanah $20 \%$.

2.3 Menghitung nilai deviasi antar alternatif pada masing - masing kriteria.

Nilai deviasi adalah hasil nilai selisih nilai kriteria suatu alternatif dengan alternatif lainnya. Nilai ini dihitung berpasangan secara menyeluruh dari semua alternatif yang ada. Cara menghitung deviasi menggunakan rumus sebagai berikut

$$
d=f(a)-f(b)
$$

Keterangan

$d \quad$ : Selisih nilai kriteria antara alternatif (deviasi)

$f(a) \quad$ : Nilai kriteria alternatif a

$f(b) \quad$ : Nilai kriteria alternatif $\mathrm{b}$

2.4 Menentukan dan menghitung nilai preferensi.

Data preferensi akan digunakan sebagai masukkan perhitungan preferensi. Data preferensi memiliki kaidah minimasi dan maksimasi, tipe preferensi serta parameter. Penentuan kaidah minimasi dan maksimasi disesuaikan dengan kriteria yang diinginkan. Namun tidak mempengaruhi proses perhitungan. Tipe preferensi disajikan dengan 6 bentuk fungsi, yaitu:

a. Kriteria Umum

$$
\begin{gathered}
\stackrel{{ }^{\mathrm{H}(\mathrm{d})}}{\longrightarrow} \\
\hline 0^{\top} \mathrm{d}
\end{gathered}
$$

Keterangan

$H(d) \quad$ : Nilai Preferensi

$d \quad:$ Selisih nilai kriteria antara alternatif

b. Kriteria Kuasi

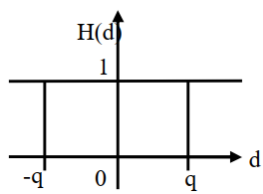

$$
\begin{aligned}
& H(d)=\left\{\begin{array}{c}
0 \text { jika }-q \leq d \leq q \\
1 \text { jika } d<- \text { atau } d>q
\end{array}\right.
\end{aligned}
$$

Keterangan

$$
\begin{array}{ll}
H(d) & : \text { Nilai Preferensi } \\
d & : \text { Selisih nilai kriteria antar } \\
\text { alternatif } & \\
q \quad: \text { Batas Indeferen (Kuartil bawah } \\
\text { atau } \left.\mathrm{Q}_{1}\right)
\end{array}
$$

c. Kriteria Preferensi Linier

$$
H(d)=\left\{\begin{array}{c}
\underset{\mathrm{r}}{\frac{d}{p} j i k a-p \leq d \leq p} \\
1 \text { jika } d<-p \text { atau } d>p
\end{array}\right.
$$

Keterangan

$$
\begin{aligned}
& H(d) \quad \text { : Nilai Preferensi } \\
& d \quad: \text { Selisih nilai kriteria antar } \\
& \text { alternatif } \\
& p \quad \text { : Batas Preferensi (Kuartil atas } \\
& \text { atau } \mathrm{Q}_{3} \text { ) } \\
& \text { d. Kriteria Level }
\end{aligned}
$$

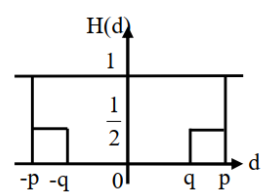

$$
H(d)=\left\{\begin{array}{c}
0 \text { jika }|d| \leq q \\
0,5 \text { jika } q<|d| \leq p \\
1 \text { jika } p<|d|
\end{array}\right.
$$

Keterangan

$H(d) \quad$ : Nilai Preferensi

$d \quad:$ Selisih nilai kriteria antar alternatif

$q \quad$ : Batas Indeferen (Kuartil bawah atau $\left.Q_{1}\right)$

$p \quad:$ Batas Preferensi (Kuartil atas $\left.\operatorname{atau} \mathrm{Q}_{3}\right)$

e. Kriteria Area 


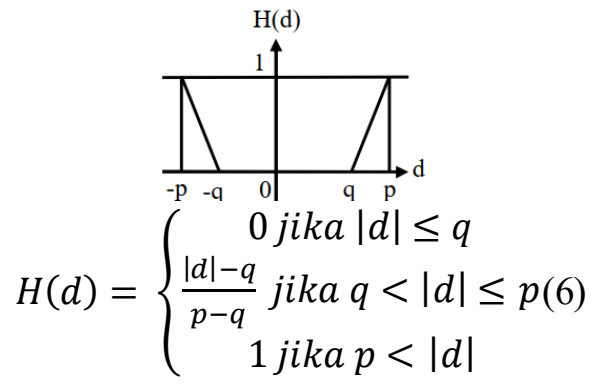

Keterangan

$H(d) \quad$ : Nilai Preferensi

$d \quad$ : Selisih nilai kriteria antar alternatif

$q \quad:$ Batas Indeferen (Kuartil bawah atau $\mathrm{Q}_{1}$ )

$p \quad$ : Batas Preferensi (Kuartil atas atau $\left.\mathrm{Q}_{3}\right)$

f. Kriteria Gaussian

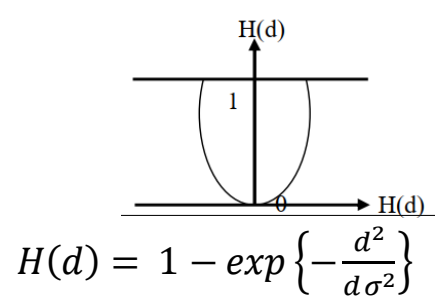

(7)

Keterangan

$H(d) \quad$ : Nilai Preferensi

$d \quad$ : Selisih nilai kriteria antar alternatif

$\sigma \quad$ : Deviasi Standar Populasi

2.5 Menghitung nilai indeks preferensi dengan rumus:

$$
\varphi(a, b)=\sum_{i=1}^{n} \pi_{i} P_{i}(a, b): \forall a, b \in A
$$

Keterangan

$$
\begin{array}{ll}
\varphi(a, b) & : \text { Indeks Preferensi } \\
\pi & : \text { Bobot Kriteria } \\
P(a, b) & : \text { Nilai Preferensi }
\end{array}
$$

Nilai Indeks Preferensi merupakan intensitas pembuat keputusan yang menyatakan bahwa alternatif a lebih baik dari alternatif $b$ dengan pertimbangan secara simultan dari seluruh kriteria. Hal ini dapat disajikan dengan nilai antara nilai 0 dan 1 .
2.6 Perhitungan leaving flow, entering flow, dan net flow

\section{a. Leaving flow}

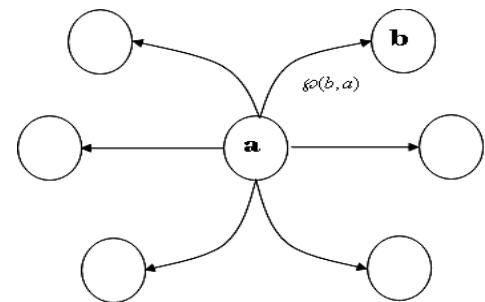

Gambar 2. Diagram Leaving Flow

$$
\varphi^{+}(a)=\frac{1}{n-1} \sum_{\substack{b=1 \\ b \neq a}}^{n} \varphi(a, b)
$$

Keterangan

$\varphi^{+}(a) \quad$ : Leaving flow

$\varphi(a, b) \quad$ : Nilai Indeks Preferensi

$n \quad$ : Jumlah Alternatif

Leaving flow adalah jumlah nilai garis lengkung yang memiliki arah menjauh dari simpul a dan ini merupakan karakter pengukuran outranking.

b. Entering flow

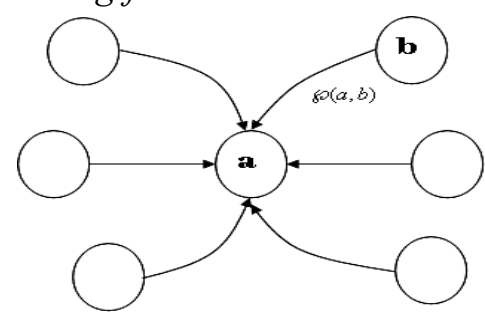

Gambar 3. Diagram Entering Flow

$$
\varphi^{-}(a)=\frac{1}{n-1} \sum_{\substack{b=1 \\ b \neq a}}^{n} \varphi(b, a)
$$

Keterangan

$$
\begin{array}{ll}
\varphi^{-}(a) & : \text { Entering flow } \\
\varphi(b, a) & : \text { Nilai Indeks Preferensi } \\
n & : \text { Jumlah Alternatif }
\end{array}
$$

Entering flow adalah jumlah nilai garis lengkung yang memiliki arah mendekat dari simpul a dan ini merupakan karakter pengukuran outranking.

$$
\begin{aligned}
& \text { c. Netflow } \\
& \quad \varphi(a)=\varphi^{+}(a)-\varphi^{-}(a)(11)
\end{aligned}
$$

\section{Keterangan}

$$
\begin{array}{ll}
\varphi(a) & : \text { Net flow } \\
\varphi^{+}(a) & : \text { Leaving flow }
\end{array}
$$


Pengembangan Rekayasa dan Teknologi, Vol 15, No. 2, Desember 2019, pp 64-70

\section{$\varphi^{-}(a) \quad$ : Entering flow}

Leaving flow adalah faktor kelebihan (strength) karena merupakan perbandingan nilai total indeks preferensi suatu alternatif dengan alternatif lainnya. Entering flow adalah faktor kekurangan (weakness) karena merupakan perbandingan nilai total indeks preferensi semua alternatif dengan suatu alternatif. Net flow menunjukkan hasil akhir yang didapat dari pengurangan nilai leaving flow terhadap nilai entering flow suatu alternatif.

2.7 Mengurutkan ranking berdasarkan net flow
Setelah mendapatkan leaving flow, entering flow, dan net flow dari masing - masing data alternatif. Hasil rekapitulasi data tersebut merupakan hasil akhir dari metode Preference Ranking Orgnization Method for Enrichment Evaluation yang dapat dibuat ranking dari nilai tertinggi ke nilai terendah berdasarkan net flow.

\section{Hasil dan Analisa}

Kriteria yang menjadi penentu lahan kritis ditunjukan pada Tabel 1. Dalam table terdapat 6 (enam) kriteria, sedangkan alternatif yang digunakan ada 14 (empat belas) yang merupakan kecamatan pada kabupaten Pemalang.

Tabel 1. Kriteria Penentu

\begin{tabular}{cccllc}
\hline Krite ria & Keterangan & referensi & q & p & bobot \\
\hline K1 & Kelerengan & Level & 0 & 1 & 15 \\
K2 & Penggunaan Lahan & Linier & 0 & 3 & 20 \\
K3 & Rawan Bencana Longsor & Linier & 0 & 2 & 10 \\
K4 & Curah Hujan & Quasi & 1 & 2 & 15 \\
K5 & Cadangan Air Tanah & Area & 1 & 2 & 20 \\
K6 & Jenis Tanah & Linier & 1 & 3 & 20 \\
\hline
\end{tabular}

Nilai evaluasi tiap kecamatan ditunjukkan pada tabel dibawah ini.

Tabel 2. Nilai Evaluasi

\begin{tabular}{ccccccc}
\hline Alte rnatif & K1 & K2 & K3 & K4 & K5 & K6 \\
\hline Bodeh & 1 & 4 & 2 & 2 & 1 & 0 \\
Ulujami & 0 & 1 & 0 & 2 & 3 & 3 \\
Comal & 0 & 2 & 0 & 2 & 2 & 3 \\
Ampelgading & 0 & 4 & 0 & 2 & 2 & 3 \\
Petarukan & 0 & 3 & 0 & 2 & 2 & 3 \\
Taman & 0 & 3 & 0 & 2 & 0 & 3 \\
Pemalang & 0 & 3 & 0 & 2 & 2 & 3 \\
Bantarbolang & 1 & 0 & 1 & 1 & 1 & 1 \\
Randudongkal & 2 & 0 & 2 & 1 & 1 & 1 \\
Warungpring & 1 & 3 & 0 & 1 & 1 & 2 \\
Moga & 1 & 3 & 2 & 0 & 1 & 2 \\
Pulosari & 3 & 2 & 2 & 1 & 4 & 0 \\
Watukumpul & 4 & 0 & 2 & 0 & 1 & 2 \\
Belik & 1 & 0 & 2 & 1 & 1 & 2 \\
\hline
\end{tabular}

Selanjutnya menghitung nilai indeks preferensi dan nilai indeks preferensi yang didapat dari menghitung nilai deviasi tiap kriteria pada suatu alternatif terhadap alternatif lainnya. 
Pengembangan Rekayasa dan Teknologi, Vol 15, No. 2, Desember 2019, pp 64-70

p-ISSN: $1410-9840$ \& e-ISSN: 2580-8850

http://journals.us m.ac.id/index.php/jprt/index

Kemudian nilai preferensi dihitung dari fungsi preferensi yang sudah ditentukan sebelumnya, dan

nilai indek preferensi didapat dari hasil perkalian preferensi dengan bobot kriterianya.

Tabel 3. Nilai Indeks Preferensi Kriteria Kelerengan

\begin{tabular}{lccccccc}
\hline \multicolumn{2}{l}{ Pe rbandingan Alte rnatif } & a & b & d & $|d|$ & P (Preferensi) & IP (Index Pref) \\
\hline Bodeh & Bodeh & 0 & 0 & 0 & 0 & 0,00 & 0,0 \\
Bodeh & Ulujami & 1 & 0 & 1 & 1 & 0,50 & 7,5 \\
Bodeh & Comal & 1 & 0 & 1 & 1 & 0,50 & 7,5 \\
Bodeh & Ampelgading & 1 & 0 & 1 & 1 & 0,50 & 7,5 \\
Bodeh & Petarukan & 1 & 0 & 1 & 1 & 0,50 & 7,5 \\
\hline
\end{tabular}

Setelah menghitung semua nilai indeks preferensi, indeks preferensi dijumlahkan dengan semua kriteria di setiap perbandingan antara suatu alternatif dengan alternatif lainnya. Kemudian menghitung nilai leaving flow serta entering flow.
Hasil akhir merupakan nilai net flow yang didapat dari nilai leaving flow dikurang nilai entering flow. Urutan ranking diambil dari nilai net flow terendah ke tertinggi karena yang diinginkan adalah lahan paling kritis.

Tabel 4. Hasil Ranking

\begin{tabular}{ccccc}
\hline Alternatif & Leaving & Entering & Net & Ranking \\
\hline Bantarbolang & $-4,55$ & 29,55 & $-34,10$ & 1 \\
Randudongkal & 6,03 & 29,36 & $-23,33$ & 2 \\
Pulosari & 23,72 & 40,90 & $-17,18$ & 3 \\
Ulujami & 15,96 & 25,96 & $-10,00$ & 4 \\
Watukumpul & 24,17 & 33,14 & $-8,97$ & 5 \\
Belik & 8,01 & 16,99 & $-8,97$ & 5 \\
Bodeh & 15,45 & 20,32 & $-4,87$ & 6 \\
Comal & 13,91 & 9,55 & 4,36 & 7 \\
Warungpring & 11,60 & 7,24 & 4,36 & 7 \\
Ampelgading & 26,22 & 9,55 & 16,67 & 8 \\
Petarukan & 21,09 & 2,37 & 18,72 & 9 \\
Pemalang & 21,09 & 2,37 & 18,72 & 9 \\
Taman & 27,24 & 8,53 & 18,72 & 9 \\
Moga & 30,45 & 4,55 & 25,90 & 10 \\
\hline
\end{tabular}

Penelitian penentuan lahan kritis di Kabupaten Pemalang dengan metode Preference Ranking Organization Method for Enrichment Evaluation memberikan hasil bahwa daerah Kecamatan Bantarbolang mendapatkan nilai net flow terendah dengan nilai $-34,10$ dan kecamatan Moga dengan nilai tertinggi.

\section{Kesimpulan}

Metode PROMETHEE telah diimplementasikan dalam menentukan lahan kritis di Kabupaten Pemalang. Hasil perhitungan yang diperoleh menggunakan metode PROMETHEE yang memiliki lahan paling kritis adalah
Kecamatan Bantarbolang. Hal tersebut dapat dijadikan rekomendasi terhadap Dinas terkait untuk dapat melakukan perbaikan terhadap daerah yang memiliki lahan kritis tersebut. Pada proses pengolahan data yang ada pada Kabupaten pemalang didapat bahwa semakin tinggi nilai evaluasinya akan semakin tinggi nilai net flownya. Kriteria yang paling mempengaruhi adalah kriteria yang memeiliki bobot presentase yang besar seperti penggunaan lahan, cadangan air tanah, dan jenis tanah.

\section{Referensi}


Pengembangan Rekayasa dan Teknologi, Vol 15, No. 2, Desember 2019, pp 64-70

[1] A. Abubakar, "Analisis Data Spasial Untuk Lahan Kritis Berdasarkan Peraturan Pemerintah No . P . 4 / V- SET / 2013," vol. 4, 2013.

[2] N. Khotimah, dan D. Istiawan, "Perbandingan Algoritma C4.5, Nä̈ve Bayes dan K-Nearest Neighbour untuk Prediksi Lahan Kritis di Kabupaten Pemalang", Akademi Statistika Muhammadiyah Semarang, 2018.

[3] D. Indrihastuti, K. Murtilaksono, dan B. Tjahjono, "Analisis Lahan Kritis Dan Arahan Rehabilitasi Lahan Dalam Pengembangan Wilayah Kabupaten Kendal Jawa Tengah", Tata Loka, vol. 18, no. 3, pp. 141-156, 2016.

[4] I. P. G. S. Putra, "Perbandingan Metode AHP Dan PROMETHEE Dalam Pengambilan Keputusan Penerimaan Beasiswa", Universitas Kristen Duta Wacana, 2014.

[5] B. Yuwono, "Sistem Pendukung Keputusan Menggunakan Metode PROMETHEE (Studi Kasus: Stasiun Pengisian Bahan Bakar Umum)", Telematika, vol. 8, no. 1, pp. 6374, 2011.

[6] M. Nassereddine, A. Azar, A. Rajabzadeh, and A. Afsar, "Decision making application in collaborative emergency response: A new PROMETHEE preference function", International Journal of Disaster Risk Reduction, vol. 38, 2019.

[7] D. A. Istiqomah, "Sistem Pendukung Keputusan Pemilihan Peserta Pelatihan Menggunakan Metode Modified Delphi, AHP dan PROMETHEE", Berkala MIPA, 25(3), September 2018.

[8] T. Imandasari, dan A. P. Windarto, "Sistem Pendukung Keputusan dalam Merekomendasikan Unit Terbaik di PDAM Tirta Lihou Kabupaten Simalungun Menggunakan Metode PROMETHEE", Jurnal Teknologi dan Sistem Komputer, vol. 5, no. 4, pp. 159-165, 2017.

[9] G. Tuzkaya, B. Sennaroglu, Z. T. Kalender, and M. Mutlu, "Hospital service quality evaluation with IVIF-PROMETHEE and a case study". Socio-Economic Planning Sciences, 2019.

[10] A. B. Nugraha, "Perbandingan Metode PROMETHEE Dengan Metode ELECTRE Pada Sistem Pendukung Keputusan Pemilihan Smartphone Android"' 